\title{
Gestão democrática da escola: mais Freire, nunca menos
}

\section{Democratic school management: more Freire, never less Gestión escolar democrática: más Freire, nunca menos}

\author{
VALDO HERMES BARCELOS \\ https://orcid.org/0000-0001-7768-1543 \\ Universidade Federal de Santa Maria \\ Programa de Pós-graduação em Antropofagia Cultural Brasileira \\ Santa Maria, RS, Brasil \\ MARIA APARECIDA AZZOLIN \\ https://orcid.org/0000-0002-4495-6827 \\ Universidade Federal de Santa Maria \\ Programa de Pós-graduação em Educação \\ Departamento de Educação \\ Santa Maria, RS, Brasil
}

\begin{abstract}
Resumo: $\mathrm{O}$ artigo aborda a gestão democrática da escola na perspectiva freireana. Foram selecionadas e tomadas como ponto de partida, para reflexão, passagens da obra freireana que entendemos conter importantes elementos epistemológicos para a construção de uma gestão democrática da escola. Propomos, a partir da obra freireana, alguns passos como forma de contribuir para a elevação do patamar das relações democráticas na gestão da escola.
\end{abstract}

Palavras-chave: Legado freireanao; Gestão democrática; Paulo Freire.

Abstract: The article deals with the democratic management of the school in the Freirean perspective. Passages of Freire's work that we believe contain important epistemological elements for the construction of a democratic school management were selected and taken as starting points for reflection. We propose, based on Freire's work, some steps, as ways to contribute to raising the level of democratic relations in school management.

Keywords: Freire's legacy; Democratic management; Paulo Freire.

Resumen: El artículo trata sobre la gestión democrática de la escuela en la perspectiva freireana. Se seleccionaron y tomaron como punto de partida para la reflexión pasajes de la obra de Freire que, creemos, contienen elementos epistemológicos importantes para la construcción de una gestión democrática de la escuela. Proponemos, a partir del trabajo de Freire, algunos pasos como una forma de contribuir a la elevación del nivel de las relaciones democráticas en la gestión escolar.

Palabras clave: Legado freireano; Gestión democrática; Paulo Freire. 


\section{INTRODUÇÃO}

Os tempos sombrios pelos quais estamos passando, de discursos negacionistas sobre a crise sanitária da Pandemia da COVID-19¹; da defesa de uma "escola sem partido"; de mirabolâncias terraplanistas; de retornos obscurantistas, combatendo teorias científicas como Teoria da Evolução das Espécies na escola; de preconceito de gêneros; de negação do pensamento intelectual crítico; de discursos de expurgo das ideias freireanas das escolas e universidades brasileiras, nada mais oportuno e urgente, que promovermos uma profunda reflexão, lúcida e generosa sobre o que queremos para a educação brasileira. Algo na perspectiva defendida pela desafiadora pergunta já feita pelo antropólogo e pensador brasileiro Darcy Ribeiro (1922-1997), quando este indagava se a educação brasileira estaria mesmo em acordo com a realidade brasileira e servindo às gentes do Brasil, (RIBEIRO, 1996). Frente a este cenário, pesquisar a obra monumental legada pelo educador brasileiro e cidadão do mundo Paulo Reglus Neves Freire (1921-1997), é imprescindível para uma gestão democrática da escola com mais dinamicidade, dialogicidade e amorosidade.

A produção intelectual e acadêmica brasileira tem um acúmulo considerável de conhecimentos e de saberes que nos permitem estabelecer um fecundo diálogo, sobre educação e democracia, com todas as pessoas e setores democráticos desse país que estejam dispostos a fazê-lo. Afinal, quantas outras nações do mundo moderno podem se orgulhar de ter em sua história um educador de espírito democrático e libertário como Paulo Freire? Pensamos que esse fato, ao mesmo tempo em que nos enche de orgulho, nos exige uma imensa dose de responsabilidade com o legado desse educador. Um legado que, se levado em conta seriamente, poderá nos ajudar a saldar a vergonhosa dívida que toda sociedade brasileira tem com o imenso contingente de brasileiros e brasileiras que, em pleno Século 21, ainda não conquistaram aquilo que Freire denominava da boniteza de aprender a ler e a escrever. Não nos esqueçamos de que vivemos em um país onde cerca de oitenta por cento das crianças que moram nas periferias das médias e grandes cidades, que cursam o segundo ano do ensino fundamental, têm mais escolaridade que os pais. José Eustáquio Romão é enfático ao alertar que "Quando se esquece dos processos culturais dos dominados é porque se quer evitar a transformação econômica, política e epistemológica e, lamentavelmente, a escola tem sido o instrumento dessa conservação. Todo conservadorismo fundase na amnésia histórica” (ROMÃO, 2005, p.132). 
Nas seções seguintes apresentaremos uma reflexão sobre a relação necessária entre educação e democracia na perspectiva freireana, como forma de acessar a elementos constituintes do pensamento de Freire para uma gestão democrática da escola e, imediatamente, passamos a apresentar alguns passos elencados a partir de algumas proposições epistemológicas e práticas da obra freireana para a construção de uma gestão democrática da escola. Concluímos com algumas reflexões sobre a importância e atualidade do legado freireano para a construção de uma gestão democrática da escola brasileira na atualidade.

\section{EDUCAÇÃO E DEMOCRACIA PRECISAM CAMINHAR JUNTAS}

"Nenhuma reflexão em torno de educação e democracia pode ficar ausente da questão de poder, da questão econômica, da questão da igualdade, da questão da justiça" (FREIRE, 2003a, p.192).

Se existe algo que jamais pode ser esquecido no legado freireano é sua constante, sua verdadeira obsessão, pelas relações democráticas de uma maneira geral na sociedade e, em especial nas relações de gestão e das políticas educacionais. Freire foi alguém que refletiu ao longo de toda sua vida de cidadão e de educador pela busca da construção de relações democráticas entre homens e mulheres e entre educadores(as) e educandos(as). Freire sempre entendeu a escola como um espaço de referência para a comunidade na qual estava inserida. Isso ficou muito explícito no período em que exerceu, por dois anos (1989-1991) a função de Secretário de Educação da cidade de São Paulo na maior cidade do Brasil e a segunda da América Latina. Corria o final da década de 80 e Luiza Erundina foi eleita prefeita de São Paulo pelo Partido dos Trabalhadores ${ }^{2}$. Paulo Freire sempre vinculou a educação libertadora das classes populares a uma escola que acolhesse amorosamente e de forma muito profissional os filhos e filhas das famílias das classes trabalhadoras. Essa era para ele, uma das mais importantes funções de uma escola que estivesse minimamente alinhada com a ética e a justiça na sociedade. Não se cansava de alertar para a necessidade da escola e dos educadores(as) populares estarem muito atentos para o fato de que o espaço institucional da escola precisaria ir além dos conteúdos e das disciplinas. A escola pode ser, e em muitos contextos é, um dos espaços privilegiados - quando não o único - com que as classes populares podem contar para a educação de seus filhos e filhas para a democracia e para a construção de sua autonomia política como cidadãos

2 Paulo Freire teve importante militância política, fez parte da primeira diretoria executiva da Fundação Wilson Pinheiro e da fundação do Partido dos Trabalhadores. 
e cidadãs. Para Freire, não é possível pensar uma educação das gentes negandolhes os direitos de acesso às condições básicas de toda e qualquer pessoa em uma sociedade democrática. Para ele,

Não é possível atuar em favor da liberdade, do respeito aos demais, do direito à voz, à participação, à reinvenção do mundo, num regime que negue a liberdade de trabalhar, de comer, de falar, de criticar, de ler, de discordar, de ir e vir, a liberdade de ser. (FREIRE, 2003a, p.191).

É a partir de reflexões desse tipo que Freire pensa a democracia como forma de relação social entre os órgãos de Estado e as demais instituições da sociedade. A escola é uma dessas instituições sociais fundamentais para a construção e manutenção da democracia em uma sociedade. A forma como a escola se organiza em suas políticas e normas de gestão podem influenciar, em muito, os caminhos que todas as demais práticas pedagógicas e educativas tomarão. É nesse sentido que, para Freire, a democracia não pode ficar restrita a um discurso sobre e/ou a algo restrito a determinados momentos da vida social e, nem mesmo, a meras letras mortas em documentos oficiais. Para Freire (2003a, p.193), "A democracia puramente formal muito pouco ou quase nada faz pela libertação dos oprimidos a não ser através do uso de espaços políticos cuja existência a própria democracia formal não tem como não admitir". O educador vai além e alerta para o fato de que a democracia que se limita a tratar apenas das questões econômicas está fadada a se reduzir a relações autoritárias e mesmo se perverter em mais um mero discurso elitista que, ao fim e ao cabo, nada mais faz que consolidar as relações de dominação e de exploração. Nas suas palavras: "As discriminações de classe, de sexo e de cor, a que se junte qualquer tipo de diminuição e de desrespeito ao ser humano, negando aquela vocação, negam também a democracia" (FREIRE, 2003a, p.193). Ao responder a uma pergunta sobre o papel da democracia na gestão da escola pública Freire acaba dando uma verdadeira aula sobre o que é a democracia e sua construção. Nas suas palavras,

A democracia não aparece por acaso nem tão pouco pelo gosto de algumas pessoas que a regalam ou a impõem às maiorias. Na verdade, a democracia é uma criação social, é uma construção política paciente e persistentemente trabalhada sobretudo em sociedades como a nossa de tradições autoritárias tão arraigadas. Há entre nós um gosto de mandar, de submeter os outros a ordens e determinações de tal modo incontido que, enfeixando nas mãos cinco centímetros de poder, o portador deste poder tende a transformá-lo em metros de arbítrio. (FREIRE, 2014, p.253). 
A partir de uma tal perspectiva de compreensão de democracia e sua importância para convivência entre os seres humanos, é que não há o que tergiversar ou fazer concessões quando a questão é a busca da construção coletiva e colaborativa da justiça social e da liberdade para todas as pessoas. É essa busca coletiva pela justiça e pela liberdade que poderá garantir ${ }^{3}$ uma sociedade democrática. É a vontade e o desejo de viver e conviver em democracia, por parte de homens e mulheres, que construirá o caminho de uma sociedade mais justa e igualitária. De outra forma, é essa participação consciente e coletiva que poderá superar as fragilidades da democracia formal limitada pelos arcabouços legais, via de regra, tão ao gosto das elites dominantes. Para Freire, não há que descuidarse do fato político e histórico de que "Nenhuma sociedade alcança a plenitude democrática se não se estrutura legalmente para defender-se, com vigor, de tais arremetidas. Mais ainda, se suas leis antidiscrininatórias não são postas em prática ou o são de maneira facciosa". É em função disso que, para Freire, há que se estar permanentemente vigilantes, pois, mesmo com toda a importância do arcabouço de leis, elas, por si só, não têm o condão de garantir a democracia. Nas suas palavras: "É indispensável que se efetivem não importa quem sejam as pessoas a quem se devam aplicar" (FREIRE, 2003a, 194).

Essa permanente vigilância se faz mais necessária, quanto mais forem as nuances de autoritarismo e de arrogância das elites que historicamente detém o controle político, econômico e cultural em uma sociedade. Imagine-se em uma sociedade onde a democracia é ainda, um exercício tão jovem como o caso da sociedade brasileira e seu contexto latino-americano. Freire foi um educador e intelectual extremamente envolvido com as questões da sociedade. Foi reconhecido no Brasil e no exterior como um ferrenho defensor da liberdade. Liberdade, essa, sem a qual a democracia perde sua vitalidade. $\mathrm{O}$ aprofundamento da democracia, para Freire, é uma necessidade, na medida em que ela é uma construção permanente. Quando era indagado se seria possível ensinar a democracia, Freire dava uma aula de educação política e de gestão democrática das instituições educacionais. Nas suas palavras,

Estou convencido de que, no hoje que vivemos, uma das experiências a ser mais enfatizadas com vistas à melhoria ou o aperfeiçoamento da democracia entre nós, considerando-se, sobretudo, nossa forte tradição autoritária, é a da criação do gosto pela liberdade. Gosto que não cresce e se robustece na ausência da responsabilidade. (FREIRE, 2003a, p.201).

3 A expressão garantir aqui utilizada não tem a ver com definitivamente pronto. Ao contrário, tem a ver, justo com aquilo que Freire denomina de inacabamento do ser humano em seu viver em comunidade. 
Para aqueles (as) que duvidavam da possibilidade de se ensinar a prática da democracia, Freire respondia:

Ensinar democracia é possível. Para isso é preciso testemunhá-la. Mais ainda, testemunhando-a, lutar para que ela seja vivida, posta em prática ao nível da sociedade global. O que quero dizer é que o ensino da democracia não se dá através apenas do discurso sobre a democracia, não raro contraditado por comportamentos autoritários. O ensino da democracia implica também o discurso sobre ela, não abstratamente feito, mas sobre ela ao ser ensaiada e experimentada (FREIRE, 2003a, p. 203).

No livro CARTAS A CRISTINA - Reflexões sobre minha vida e minha práxis (2001), Freire na $14^{\mathrm{a}}$. Carta, que leva o título de Educação e Democracia, elenca alguns pontos que considera fundamentais para esse ato pedagógico de ensinar a democracia e que consideramos extremamente relevantes para uma atuação na gestão democrática que é o tema orientador dessa nossa reflexão. Vamos apresentá-los de forma sucinta a seguir:

- Ensinar democracia é possível sim, mas não para quem se desencanta da terça para a quarta-feira;

- Ensinar democracia é possível, mas não é tarefa para quem pensa que o mundo se faz na cabeça dos bem-intencionados;

- Ensinar democracia é possível, mas não é tarefa para quem, só paciente, espera tanto que perde o trem da história;

- Ensinar democracia é possível, mas não é tarefa para quem percebe a história e nela atua mecanicistamente.

Nesse ensinar democracia, o papel de professores e professoras é decisivo. O espaço da escola pode se constituir em um ambiente privilegiado para o exercício diário, cotidiano e responsável da democracia. No entanto, para que isso comece a acontecer se faz necessário e urgente que os processos de gestão democrática das relações educativas sejam desejados, sincera e honestamente por todos àqueles e àquelas que convivem nesse ambiente educacional que é a escola. Como já alertou Freire, a democracia não pode ficar resumida a um discurso. Ela precisa ser experienciada, ser vivenciada para assim, ser aprendida. Para Freire, a maneira mais certeira de se fazer isso é incentivando os educadores (as) a trazerem "A vida mesma para dentro da sala de aula" (2016, p.204). A maneira mais apropriada para fazer-se isso é por meio do incentivo à reflexão crítica dos educandos (as) sobre os temas da sua realidade.

Não fica nem um pouco difícil perceber-se, em proposições como essa apresentada por Freire, mesmo muitas décadas depois, o que ele já defendia no 
seu livro fundamental Pedagogia do Oprimido ${ }^{4}$ na década de 60 do Século passado. A pertinência e a atualidade da obra freireana se mostram, a cada ano que passa, algo mais inquestionável. Um dos grandes conhecedores e divulgadores do legado freireano no Brasil e no continente Sul-Americano, o professor Reinaldo Matias Fleuri, na introdução do livro REINVENTAR O PRESENTE...pois o amanhã se faz, na transformação do hoje, assim se manifesta sobre a atualidade e a vitalidade da obra freireana: "Seu pensamento está vivo em nossas lutas e utopias. Sua memória se mantém em seus escritos e a vitalidade de suas propostas se refaz nas críticas e reinvenções que estudiosos, profissionais e militantes vêm elaborando sob diferentes pontos de vista e em variados contextos" (FLEURI, 2008, p.11).

Pensar uma escola que se oriente por relações democráticas exige que atentemos para as experiências vividas dos educandos (as). Faz-se fundamental buscarmos perceber quais experiências com relações democráticas carregam os (as) educandos(as) que chegam à escola. Vivemos em uma sociedade de orientação patriarcal ${ }^{5}$, na qual a busca de controle e de dominação são uma realidade histórica difícil de negar. A escola que optar por uma organização de gestão democrática tem um papel decisivo para que educandos (as) tenham a oportunidade real de experienciar a democracia. Freire (1993) ao refletir sobre política e educação fazia questão de ressaltar o fato de que os educandos e educandas se envolvem com mais facilidade, em processos educativos que lhes sejam familiares em palavras, gestos, enfim, em acordo com suas experiências vividas.

Pensar uma gestão democrática na escola, a partir de algumas proposições freireanas, é uma necessidade e se faz urgente no contexto social e político que vivemos na atualidade, bem como, é uma forma de pensar e implementar alternativas de resistência aos atuais ressurgimentos de autoritarismos, populismos e neofascismos ${ }^{6}$ no mundo em geral e no Brasil em particular.

4 O livro Pedagogia do Oprimido foi como que um aprofundamento e um adensamento dos escritos de Freire até então. Com Pedagogia do Oprimido Freire apresenta de forma incisiva, e radical, suas análises sobre as injustiças sociais numa sociedade organizada na perspectiva de opressores(as) e de oprimidos(as). O caráter fortemente político da obra freireana ganha, com Pedagogia do Oprimido, um impulso que não mais pode ser freado. Talvez essa tenha sido uma das motivações para tantos ataques que Freire e sua obra receberam ao longo do tempo de parte das elites reacionárias e dos defensores de uma educação elitista, de orientação bancária e discriminatória. Esses ataques têm recrudescido nos últimos tempos, particularmente no Brasil, com a ascensão a Presidência do senhor Jair Bolsonaro.

5 Para ler sobre a Cultura Patriarcal: Habitar Humano. Humberto Maturana \& Ximena Dávila. Palas Athena, 2009. MATURANA \& VERDEN-ZÖLLER, Amar e Brincar - fundamentos esquecidos do humano. Palas Athena, 2004.

6 Sobre ressurgimentos autoritários ver obra POPULISMO E FASCISMO - os maiores inimigos da democracia. Barcelos, V. Editora OIKOS. São Leopoldo, 2020. 


\title{
A GESTÃO DEMOCRÁTICA DA ESCOLA E O LEGADO FREIREANO
}

\begin{abstract}
"Não há história sem homens, como não há uma história para os homens, mas uma história de homens que feita por eles, também se faz" (FREIRE, 2016, p.204).
\end{abstract}

Uma das críticas que se escuta de parte daqueles (as) que insistem em não reconhecer a potencialidade e a atualidade da obra freireana, é que Freire foi um pensador que se dedicou exclusivamente à educação de jovens e adultos. Tal crítica tanto se deve ao desconhecimento da densidade e da profundidade epistemológica e prática da obra de Paulo Freire, quanto de uma intenção de desqualificá-la frente ao debate da educação no Brasil. Freire deixa muito evidente a importância das práticas políticas democráticas no interior das organizações educacionais quando, por exemplo, adverte que a emancipação, a libertação de homens e de mulheres é algo que passa, necessariamente, pela compreensão de que "Ninguém liberta ninguém, ninguém se liberta sozinho: os homens se libertam em comunhão" (FREIRE, 2016, p. 95). As organizações educacionais são espaços privilegiados para que essa libertação ocorra desde que atentemos para a necessidade de valorizar a participação e as ações colaborativas entre todos os participantes dessa comunidade. O chamamento e a abertura de espaços para a participação de todos os membros da comunidade, tanto interna da escola quando a comunidade envolvente, é fator decisivo para que uma gestão se efetive como uma gestão realmente democrática.

São notórios os exemplos de passagens da obra freireana, em que ele reafirma a necessidade de acolhimento afetuoso da comunidade na escola. Segundo ele, a participação da comunidade não pode, de forma alguma, se resumir a uma mera ação burocrática e pontual do tipo recebimento de boletins, participação em atividades e datas festivas etc. A aprendizagem e a adesão às propostas de uma gestão democrática são diretamente proporcionais ao envolvimento entre a comunidade escolar e a comunidade extraescolar.

Para Freire, é muito importante à relação da escola com a comunidade em que está inserida, para a instalação de fato de uma gestão democrática. No entanto, para que isso aconteça, se faz necessário que os educadores(as) tomem a iniciativa de buscar conhecer a comunidade a que pertencem os(as) educandos(as) que na escola chegam. Ao abrir-se para a comunidade, a escola assume na prática, o seu papel político e democrático de transformar a educação num ato político e emancipatório. Em seu livro Pedagogia da Autonomia (1996), Freire deixa muito explícita essa sua preocupação com a gestão democrática ao narrar a história de 
um professor que, em certa ocasião ao visitar uma exposição de fotografias feita na escola em que trabalhava, ficou impressionado com o seu desconhecimento da comunidade em que a escola estava inserida. Nas palavras do professor,

\begin{abstract}
Visitei uma sala em que se expunham fotografias das redondezas da escola. Fotografias de ruas enlameadas, de ruas bem postas também. Fotografias de recantos feios que sugeriam tristeza e dificuldades. Fotografias de corpos andando com dificuldade, lentamente, alquebrados, de caras desfeitas, de olhar vago. [...] dois professores faziam comentários em torno do que lhes tocava mais de perto. De repente, um deles afirmou: "Há dez anos ensino nesta escola. Jamais conheci nada de sua redondeza além das ruas que lhe dão acesso. Agora, ao ver esta exposição de fotografias que nos revelam um pouco de seu contexto, me convenço de quão precária deve ter sido a minha tarefa formadora durante todos estes anos. (FREIRE, 1996, p.52)
\end{abstract}

A reflexão sobre a prática cotidiana de cada educador (a), bem como sobre a forma como entende que deve ser a gestão de sua escola, é um exercício pedagógico não só necessário, como pode fazer toda a diferença para a implementação de uma gestão democrática para além das normas e regras burocráticas. Assim como aprendemos com o outro no processo de aprendizagem, aprendemos, também, a ser um gestor democrático na convivência, no diálogo e na participação efetiva e afetiva das atividades da escola. Freire fazia questão de deixar bem explícita sua preocupação, quando afirmava que a construção democrática nas relações da instituição escola jamais podia ficar restrita a uns poucos "iluminados e bem intencionados" (2014, p.155) e esquecer-se, por exemplo, de abrir espaços de participação, por exemplo, às merendeiras, aos pais, aos alunos, aos auxiliares administrativos, aos zeladores, enfim, não cair na armadilha tão frequente de, em nome da defesa dos direitos do outro tomar para si o direito de falar pelo outro (FREIRE, 2016).

A libertação e a assunção da autonomia daqueles e daquelas que se encontram em condição de subjugação não pode ser vista como uma libertação que vem de outro - o libertador - como algo que vem de fora. Para Freire, essa libertação precisa ser entendida como uma libertação de pessoas - sujeitos de sua história - pois, não podemos nos esquecer, nunca, que em educação estamos lidando com homens e com mulheres no mundo. Como descrevia Freire, lidamos com gente. Nas suas palavras: "Estamos lidando com homens e não com coisas. Por isso, se não é autolibertação - ninguém se liberta sozinho -, também não é libertação de uns feita por outros. Não se pode realizar com os homens pela "metade". E, quando o tentamos, realizamos a sua deformação" (FREIRE, 2016, p.97). Ao adotarmos essa perspectiva epistemológica, estaríamos dando um importante e decisivo passo na passagem de uma realidade vivida para uma 
realidade imaginada, sonhada. Estaríamos abrindo mão da pretensão de alguém que ensina algo ao outro, não raro, coisas que esse outro já sabe, e que por desconsiderarmos suas vivências não percebemos que ele sabe. Pode até ser um saber de outro jeito organizado e diferente de nosso saber acadêmico e científico, mas, que lhe é de serventia para o seu viver. Algo no sentido da fala do agricultor alfabetizando que diz: "Nós já sabe derrubar o pau. O que nós quer saber é se você vai tá com nós na hora do tombo do pau” (FREIRE, 2003a, p.35). Esse estar junto na realidade vivida leva educando (a) e educador (a) a serem parceiros numa tarefa cooperativa. Nesse processo de estar junto e cooperar, se encontram duas pessoas, dois sujeitos e não um sujeito que sabe, que ensina e um objeto a ser lapidado. Em tal tipo de processo acontece aquilo que Freire busca em toda sua obra desde o essencial Pedagogia do Oprimido: sujeitos "cointencionados à realidade, se encontram numa tarefa em que ambos são sujeitos no ato, não só de desvelá-la e, assim, criticamente conhecê-la, mas, também, no ato solidário de recriar juntos este conhecimento" (FREIRE, 2016, p.101).

Ao adotarmos essa premissa pedagógica, solidária e libertária, estaríamos levando em consideração o que propõe o legado freireano quando nos mostra que a função do (a) educador (a) e educadora, sinceramente comprometidos com a autonomia e com a libertação de educandos (as), é reconhecer e admitir suas limitações não como incapacidades, mas, sim, como partes instituintes de sua trajetória como ser histórico no mundo em que vive. Para Freire, uma das melhores qualidades de um educador é dar o testemunho aos seus educados (as) de que "la ignorância es el punto de partida de la sabiduria, que equivocar-se no es un pecado, sino que forma parte del proceso de conocer y que el error es un momento de la búsqueda del saber. (FREIRE, 2003b, p.54).

O papel de um(a) gestor(a) democrático, - como de um educador (a) - passa, necessariamente, por ter a humildade de reconhecer que não sabe tudo, mas que sabe um pouco. Sabe que a construção e a execução de um projeto de gestão democrática da escola, passa pela construção de um projeto que seja comum a todos (as) os membros da comunidade que assim o desejarem.

\section{PASSOS PARA UMA GESTÃO DEMOCRÁTICA NA ESCOLA}

Todo (a) educador (a) sabe que, ao exercer sua atividade educativa na escola está sendo orientado por uma determinada concepção de gestão do processo educativo escolar. Com certeza, que nem sempre isso se faz presente nas reflexões que esses educadores (as) fazem em seu cotidiano. De outra forma, o cotidiano em que educadores (as) estão mergulhados, com muita frequência, os leva a não refletir sobre um grande número de situações que ocorrem no 
dia a dia. As causas dessa condição são inúmeras e não seria o caso de nesse espaço enumerá-las todas. Mas quem é educador no Brasil sabe o que significa assumir essa profissão em uma sociedade em que todos se jactam em discursar sobre a importância da educação, sobre a prioridade da educação, enfim, sobre a educação como algo que vai tirar o país de suas dificuldades econômicas, diminuir as injustiças sociais, que vai diminuir o desemprego etc.

O momento atual da crise sanitária mundial decorrente da Pandemia da COVID-19 é apenas uma das situações em que a todo momento escutamos de políticos, de comunicadores, de empresários, de gestores, e até de educadores, que a educação é uma atividade essencial. A questão que se coloca é:

- se é assim reconhecida como essencial porque não está tendo o tratamento condizendo com essa essencialidade?

- por que os profissionais da educação, somente após 14 meses de pandemia e de escolas fechadas, foram incluídos nas prioridades de atenção por parte dos governantes e dos gestores da saúde?

- por que a atenção governamental para com as crianças e adolescentes filhos das famílias mais desfavorecidas economicamente e que estudam na escola pública, foram como que abandonadas pelos órgãos de gestão pública da educação básica?

Como escrevemos anteriormente, as questões seriam difíceis de enumerar todas. No entanto, a resposta é muito simples. Existe um discurso histórico e demagógico de que a educação é uma dimensão realmente importante, fundamental, essencial para a vida das pessoas e, consequentemente, para a vida decente em um país. Mas, como muito bem alertava Freire, há que materializarmos nossas palavras, nossos discursos por meio de nossas ações cotidianas. Como ensinava Freire (FREIRE, 1996, p.34) "Ensinar exige a corporeificação das palavras pelo exemplo". Poucos são os territórios da educação escolar em que a falta dessa coerência entre discursos e ações práticas são tão evidentes quanto o da gestão democrática das relações educacionais. São muito frequentes as narrativas de educadores (as) que explicitam a distância que, por muitas ocasiões, separa o que declaram alguns gestores (as) de suas reais práticas cotidianas no exercício da gestão. Como já citado, em muitos casos os (as) gestores (as) nem sequer percebem essa contradição. Essa não percepção tem a ver, em muito, da mesma forma que o professor, com a falta de reflexão sobre sua prática cotidiana.

Como forma de deixar nossa contribuição para pensarmos uma gestão democrática da escola elencaremos, a partir de algumas proposições freireanas, alguns passos que, em nosso entendimento, poderão iniciar caminhos rumo a uma mudança em nossas práticas de gestão nas instituições educacionais. Não os apresentamos como fórmulas, ou chaves para abrir todas as portas, mas, 
sim, como convites aos colegas educadores (as) para uma reflexão, sobre o que queremos manter daquilo que até aqui construímos, como práticas necessárias para a implementação de uma gestão democrática da escola.

Para a construção de uma gestão democrática da escola é fundamental levar em consideração que:

- É necessário aprender a escutar - Entre as tantas qualidades que se espera de um gestor que busque uma relação de gestão democrática, está a de saber escutar todos os componentes da comunidade. Esse ato de escutar está para além de ouvir. A expressão escutar aqui tomamos na sua origem do latim auscultare que quer dizer buscar se entender com o outro. Significa dar atenção para aquilo que vem de dentro. Enfim, estar atento às emoções que o outro deixa fluir no cotidiano das relações na escola. Freire (2003b) advertia que não é falando que se aprende a falar, mas, sim, é escutando que se aprende a falar. Não será um gestor (a) democrático aquele (a) que não souber escutar;

- Mudar é difícil, mas é possivel - Mudar hábitos e costumes é algo que exige de todos (as) nós, um desejo sincero de transformação em nossas vidas. A ação de educar e de educar-se é uma dessas ações que fazem parte de nosso devir cultural. Está, portanto, encharcada pela cultura em que vivemos. A decisão política de buscar uma gestão democrática das relações educacionais não escapa - nem poderia - dessa condição. Afinal, como ensinava Freire não podemos esquecer que em educação lidamos com gente. Freire não se cansava de alertar que em educação lidamos com gente e não com objetos ou coisas. Para ele não podemos, por mais que me atraia a vontade de mandar ou de sucumbir às meras teorias, esquecer, descuidar, das questões cotidianas culturais e políticas de todos os membros da comunidade escolar em que exerço a gestão. Esse compromisso com o reconhecimento se faz algo fundamental na educação em geral e para uma gestão democrática, se faz uma condição necessária. Mais uma vez é importante salientar que não basta dizer que desejamos a mudança, é necessário dar provas dessa vontade. Como fazer isso? Por meio de minhas ações cotidianas nos espaços de gestão;

- Corporeificação das palavras pelo exemplo - Se precisamos, o tempo todo, falar da responsabilidade, da honestidade, da liberdade, é porque não estamos sendo responsáveis, não estamos tendo ações de responsabilidade com nós mesmos e com os outros. Se falamos muitas vezes sobre a honestidade é porque não estamos sendo honestos em nossas ações. Via de regra, quando falamos sobre honestidade é para apontar a falta desta nas atitudes dos outros e/ou nas instituições. Da mesma forma, não basta falarmos sobre a necessidade de uma gestão democrática, precisamos refletir sobre nossas ações práticas de gestão e verificar se estamos sendo honestos, responsáveis, se estamos incentivando 
a participação livre de todos(as), se estamos escutando o outro(a), se estamos realmente buscando a mudança. A promoção de uma gestão democrática exige que assumamos, radicalmente, uma prática democrática em nossas relações educacionais. Se para Freire (2003a), devemos ter muito claras nossas concepções políticas como educador, para ser um gestor democrático essa definição é uma condição necessária;

- Aceitar o protagonismo dos demais - Paulo Freire no livro El grito Manso (2003b, p.55) faz uma advertência que consideramos uma exigência para qualquer gestor que esteja buscando o exercício de uma gestão democrática na escola. Para ele, "É necessário não pensar que sou o único no mundo que pode fazer coisas certas". Tal forma de se comportar, por seu lado, exige que o gestor tenha humildade em seu fazer cotidiano, que não alimente rancores com aqueles(as) que pensam diferente e/ou que conseguem fazer aquilo que no momento não consigo realizar. Humildade, para Freire, significa respeitar o outro que se mostra capaz de fazer o que nós não estamos conseguindo fazer. Um gestor humilde é aquele que, ao mesmo tempo em que não exerce o mando em relação aos que estão em sua gestão, também não aceita ser humilhado. Aceitar o protagonismo de todos aqueles (as) que desejarem participar é um passo decisivo para uma Gestão democrática e para a execução de um projeto comum de trabalho educativo que promova a liberdade e a responsabilidade junto à comunidade;

- É necessário inventar situações criadoras - A atividade de gestão é, por sua própria natureza, uma atividade complexa. Como tal, exige que o gestor democrático leve em consideração o maior número possível de elementos que compõem essa atividade na escola. Assim como na prática pedagógica cotidiana, o educador (a) precisa estar ciente de que suas alternativas para o fazer docente, não são algo que brotam do acaso ou, como diria Freire (2003b, p.54), "Não caem do céu...Saberes y virtudes deben ser creados, inventados por nosotros". Na gestão democrática, isso precisa ser tomado como uma rotina. Uma gestão democrática exige que o (a) gestor (a) exercite a capacidade criadora de si próprio (a), bem como incentive a de seus colaboradores e colaboradoras. $\mathrm{O}(\mathrm{a})$ gestor(a), na gestão democrática, não deve nunca temer as propostas e iniciativas daqueles(as) que participam de sua comunidade de gestão. Ao contrário, deve incentivá-las. Com isso, estará reafirmando seu respeito pelo outro;

- É fundamental estar atento ao novo - A abertura para a aceitação daquilo que se apresenta como novo não significa, segundo Freire (1996), aceitar algo pelo simples fato de ser uma novidade ou uma "moda". Não raro, na educação em geral e na gestão em especial, somos bombardeados por "novidades" que de novo nada contêm ou, simplesmente, são "inovações" a serviço de uma visão oportunista ou de exploração renovada. Como forma de evitar cair nessa armadilha, Freire sugere 
que fiquemos atentos, pois, "O velho que preserva sua validade ou que encarna uma tradição ou marca uma presença no tempo continua novo”. (FREIRE, 1996, p.35). A gestão nos espaços educacionais - mas não só nesses - particularmente no Brasil, com frequência é afetada pelas trocas de orientações políticas e ideológicas que intentam imprimir suas propostas, não raro, sem o diálogo e sem a conversa amorosa e respeitosa com os participantes da comunidade. Essa prática diz muito do traço autoritário que ainda persiste em boa parte de nossa elite. $\mathrm{Na}$ gestão democrática, esse é um ponto que precisa ser tratado com muita calma, e sempre levando em consideração aquilo que realmente é novo, e que tem contribuições para qualificar nossos espaços educativos como espaços promotores da cidadania e da construção da autonomia de educandos (as) e de educadores(as);

- Há que ter alegria e esperança - Esperança e alegria foram duas dimensões que acompanharam a vida de Freire. Sempre soube enfrentar as maiores agruras com otimismo e com esperança de que a mudança é possível. Uma de suas frases que acreditamos dizer muito sobre isso é quando afirma no livro O grito Manso que "la realidad no és a si, está a si" (2003, p.35). Como já referenciamos anteriormente nesse texto, quando Freire sentencia que o que temos como realidade não é algo imutável. Ao contrário, é o mundo que vivemos e que podemos transformar com nossa intervenção. Importante pensar o momento político que estamos vivendo hoje no Brasil e entender esse chamamento de Freire como um desafio, uma convocação a participar efetivamente e politicamente na educação em geral e nas práticas de gestão democrática em especial. Essa seria uma forma de manter a esperança na potencialidade da educação como possibilidade de libertação, bem como de resistência aos ataques e tentativas de desqualificação que Freire e seu legado estejam sofrendo. Da mesma forma, é fundamental manter a esperança, do verbo esperançar, justamente para reafirmar a necessidade do pensar crítico, da ação, da não aceitação das situações e instituições, simplesmente, como se apresentam. Freire, desde o Pedagogia do Oprimido ressalta que a existência humana se faz e refaz na esperança e no sonho. Freire não se cansava de reafirmar que a esperança não era suficiente, mas, sim, necessária. Não acreditava que a esperança por si só fosse capaz de transformar a realidade. Por isso, se faz necessário partir para a ação, para a busca daquilo que se deseja realizar. Mesmo nos momentos mais difíceis e sombrios politicamente, é necessário manter a alegria e a esperança de que a mudança é possível. O verbo esperançar é a materialização na prática da busca incessante da realização dos sonhos, sem os quais, segundo Freire, não há existência humana. 
Esses passos que elencamos estão abertos às contribuições de todos (as) aqueles(as) estudiosos(as) e pesquisadores(as) que se interessam por uma gestão democrática da escola. Não os apresentamos como elementos de uma fórmula pronta, mas, sim, como uma contribuição e um convite a uma reflexão generosa e esperançosa.

\section{CONSIDERAÇÕES FINAIS}

"Não há educação sem amor. Quem não é capaz de amar os seres inacabados não pode educar. Não há educação imposta. (FREIRE, 1979, p.29)

Chegando a esse momento esperamos ter deixado um convite humilde e esperançoso no sentido de ter apresentado algumas reflexões sobre o legado freireano na perspectiva da ampliação, nos espaços educativos escolares e mesmo não escolares, de processos e de práticas de gestão que se pautem pela construção de relações democráticas entre os membros da comunidade.

Entendemos que o legado freireano se apresenta atual e de extrema pertinência para a resistência aos ressurgimentos autoritários, bem como pode ser uma alternativa teórica e prática para a construção e/ou ampliação de uma proposta de gestão democrática da/na escola.

O legado freireano, ao dialogar com a realidade, nos apresenta de forma direta e consistente teoricamente alternativas políticas que trazem em seus pressupostos importantes elementos para a transformação dessa realidade mesmo nos momentos mais difíceis em que possamos estar vivendo. Sua obra é eivada de sentimentos como a esperança, a alegria, o respeito ao outro, o reconhecimento aos saberes da experiência, com a cooperação entre homens e mulheres independentemente de sua etnia, seu gênero, enfim, a obra freireana é um chamamento para a construção de relações democráticas na educação em geral e como uma consequência, um importante celeiro de sugestões epistemológicas e práticas para quem quiser pensar uma gestão democrática da escola brasileira.

Impossível não ressaltar nessa conclusão, que Freire não se cansava de alertar para o fato de que não é possível ser um(a) educador(a), se não for capaz de amar o mundo, de amar os(as) educandos(as), de amar a vida. Dessa forma, pensar uma gestão democrática, a partir dessas proposições, significa aceitar o desafio freireano de que, assim como não há educação imposta, também não poderá haver uma gestão democrática imposta. 


\section{REFERÊNCIAS}

BARCELOS, V. POPULISMO E FASCISMO - os maiores inimigos da democracia. OIKOS. São Leopoldo, 2020.

BRANDÃO, C. R. A educação como cultura. Campinas. Mercado Aberto, 2002.

FLEURI, R, M. REINVENTAR O PRESENTE ...pois o amanhã se faz na transformação do hoje. Fortaleza. UFC, 2008

FREIRE, Paulo. Pedagogia dos sonhos possíveis. R Rio de Janeiro: Paz e Terra, 2014.

FREIRE, Paulo. Pedagogia do Oprimido. Rio de Janeiro. Paz e Terra, 2016. $\left(60^{a}\right.$. Edição).

FREIRE, Paulo. Cartas A Cristina - Reflexões sobre minha vida e minha práxis. São Paulo. UNESP, 2001.

FREIRE, Paulo. Educação e Mudança. São Paulo. PAZ e TERRA, 1979.

FREIRE, Paulo. Política e Educação. São Paulo. Cortez, 2003a.

FREIRE, Paulo. Pedagogia da Autonomia: saberes necessários à pratica docente. Rio de Janeiro: Paz e Terra, 1996.

FREIRE, Paulo. El grito manso. Buenos Aires: siglo veintiuno, 2003b.

MATURANA, Humberto; DÁVILA, Ximena. Habitar humano: em seis ensaios de Biologia-Cultural. São Paulo: Palas Athena, 2009.

MATURANA, Humberto.; VERDEN-ZÖLLER,Gerda. Amar e brincar fundamentos esquecidos do humano. São Paulo. Palas Athena, 2004.

PAZ, O. Laberinto de la soledad. Obras Completas. V. 8. México. Fondo de Cultura Económica, 1994. 
REVISTA DE EDUCAÇÃO AEC. Paulo Freire, Brasília, v.27, n. 106, p.9-12, jan/mar. 1998.

RIBEIRO, Darcy. O povo brasileiro - a formação e o sentido do Brasil. São Paulo. Companhia das Letras, 1996.

ROMÃO, José Eustáquio. Multiculturalidade na Educação. Revista Sociedade, Educação \& Culturas. N.23, 2005. (pg.125-135). Porto-Portugal.

\section{Valdo Hermes Barcelos}

Professor titular da Universidade Federal de Santa Maria. Doutor em Educação (UFSC). Pesquisador Produtividade em Pesquisa Nível 1D - CNPq. Membro da Academia Internacional de Artes, Letras e Ciências - ALPAS - 21 - Cadeira Paulo Freire. Membro da Academia Santa Mariense de Letras-ASL - Cadeira Cyro Martins. Membro da Casa do Poeta de Santa Maria. Consultor MEC/UNESCO - MEC/MMA - CYTED - INPA - MCT. Membro Anistia Internacional Brasil. E-mail: vbarcelos@terra.com.br

\section{Maria Aparecida Azzolin}

Doutora em Educação (UFSM). Mestra em Educação Unipampa (Jaguarão).

Pedagoga e Licenciada em História Psicanalista (ABRAPSI). E-mail: cidaazzolin@gmail.com 